\title{
O ESPORTE NA RESSOCIALIZAÇÃO DE JOVENS EM CONFLITO COM A LEI - UM ESTUDO DE CASO
}

\author{
Scheila Espindola Antunes \\ Gerais, Brasil \\ Otávio Guimarães Tavares da Silva \\ Universidade Federal do Espírito Santo, Vitória, Espírito Santo, Brasil
}

Instituto Federal de Educação, Ciência e Tecnologia do Sudeste de Minas Gerais, Barbacena, Minas

\begin{abstract}
Resumo
Existe em torno do esporte um discurso bastante disseminado sobre suas potencialidades no trato com valores éticos e morais. Embutida nesse discurso, está uma premissa que o aponta como ferramenta de elevado potencial dentro de ações sociais que intencionam, dentre outros, combater a criminalidade na infância e na juventude. O objetivo do estudo foi identificar e tentar compreender os sentidos e significados do esporte para quatro jovens em conflito com a lei, inseridos em um projeto social de esporte para cumprimento de medida socioeducativa do tipo PSC. Para três dos quatro jovens, o esporte não ajuda na reflexão sobre a infração cometida e tampouco influencia seus comportamentos e suas atitudes na vida em sociedade.
\end{abstract}

Palavras-chave: Adolescente. Esportes. Projetos. Comportamento social.

\section{Introdução}

Existe em torno do esporte um discurso bastante disseminado sobre suas potencialidades no trato com valores éticos e morais. Embutida nesse discurso, está uma premissa que o aponta como ferramenta de elevado potencial dentro de ações educativas que intencionam alcançar populações em situação de risco social (NICHOLS, 2007; 2004; BAILEY, 2005; THOMPSON, 2005; STEENBERGER; TAMBOER, 1998; ZALUAR, 1994). Esse processo parece ter tomado forma e se expandido a partir do surgimento do terceiro setor entre as décadas de 1960 e 1970.

Segundo Thompson (2005), o terceiro setor ${ }^{1}$ surgiu como uma alternativa para a criação de espaços de ação cidadã e democrática na tentativa de combater o autoritarismo exercido pelos regimes militares. Em uma das principais esferas de atuação do terceiro setor, a educação, o esporte educacional aparecia como um braço de ação nos projetos sociais. Segundo Zaluar (1994), esse processo ficou mais evidente na década de 1980, quando houve aumento significativo na implantação de projetos sociais em comunidades carentes, dentre os quais a maior parte empregava o esporte na perspectiva educacional como mecanismo de ação. Esse processo, por sua vez, acabou contribuindo para reforçar a premissa atual que aponta o esporte educacional como um importante mecanismo dentro de ações socioeducativas.

\footnotetext{
${ }^{1}$ Associações e entidades sem fins lucrativos como organizações não governamentais (ONGs) e organizações da sociedade civil de interesse público (OSCIPs) são exemplos do tipo de entidade que constitui o terceiro setor. 
Um levantamento sobre as produções brasileiras no período de 2010 a 2014, no campo da Educação Física, encontrou 31 pesquisas sobre projetos sociais que utilizam o esporte como mecanismo de ação social e educacional dentro de um universo de 2.081 publicações. Com esse levantamento, foi possível identificar a predominância de pesquisas de campo, sobretudo, com ênfase na análise de dois programas sociais do governo federal, o Programa de Esporte e Lazer na Cidade (PELC) e o Programa Segundo Tempo (PST). Constatou-se, ainda, que os 31 estudos centraram suas análises em questões relativas a ingresso, permanência/evasão dos sujeitos e/ou desenvolvimento/manutenção dos programas, com enfoque na perspectiva dos agentes dos projetos e não dos participantes. Nenhum desses estudos apresentou evidências conclusivas sobre os efeitos do esporte dentro dos projetos/programas sociais (ANTUNES, 2015).

Nichols (2004), Bailey (2005) e Janssens (2004) estudaram o uso recorrente do esporte como mecanismo de ação em programas sociais no Reino Unido e em demais países da Europa. Nichols (2004) investigou programas sociais de intervenção primária, secundária e terciária $^{2}$. Bailey (2005) realizou um estudo de revisão sobre o papel da educação física e do esporte na inclusão social. Janssens (2004) investigou boas práticas educacionais realizadas a partir e por meio do esporte. Ao final de seus estudos, os três autores apontaram para o mesmo problema, a falta de evidências conclusivas sobre os efeitos do esporte tanto na inclusão social como no combate à criminalidade. Segundo eles, o fato está relacionado à falta de instrumentos específicos para a avaliação dos programas/projetos sociais, aliada ao ainda reduzido número de pesquisas que consideram a perspectiva dos participantes. É nesse sentido que o presente estudo se justifica.

Assim, o objetivo do estudo realizado foi identificar e tentar compreender os sentidos e significados do esporte para quatro jovens em conflito com a lei, inseridos em um projeto social de esporte para o cumprimento de medida socioeducativa do tipo Prestação de Serviço Comunitário (PSC). Tenta-se dar visibilidade aos entendimentos e aos sentidos que esses jovens atribuem ao esporte dentro do processo de ressocialização ao qual são submetidos durante o cumprimento da medida socioeducativa que lhes foi determinada judicialmente.

\section{Metodologia}

A investigação se caracteriza como um estudo de caso (LAVILLE; DIONNE, 1999). Tal investigação permitirá inicialmente fornecer explicações no que tange diretamente ao caso considerado e aos elementos que lhe marcam o contexto. Todavia, temos razões para considerá-lo como típico de um conjunto mais amplo do qual se torna representante. Neste contexto, em termos de abordagem, este estudo de caso assume características etnográficas (HAMMERSLEY; ATKINSON, 1993, p. 1). Segundo os autores, o termo 'etnografia'

in its most characteristics form it involves the ethnographer participating, overtly or covertly, in people's daily lives for an extended period of time, watching what happens, listening to what is said, asking questions - in fact, collecting whatever data are available to throw light on the issues that are the focus of the research.

Tentamos construir uma etnografia reflexiva que "mobiliza os diversos instrumentos da pesquisa etnográfica sem hierarquizá-los a priori, esforçando-se para ajustar o instrumento ao objeto de pesquisa" (BEAUD; WEBER, 2015, p. 196). Nesse sentido, a pesquisa de campo acompanhou quatro jovens em conflito com a lei, do sexo masculino, com idades entre 16 e

\footnotetext{
${ }^{2}$ Intervenção primária: comunidades carentes não classificadas em risco ou vulnerabilidade social; intervenção secundária: comunidades em risco ou vulnerabilidade social; intervenção terciária: comunidades ou grupos envolvidos com o crime.
} 
18 anos, durante o cumprimento de medida socioeducativa em um projeto esportivo de intervenção secundária/terciária existente em Barbacena - MG. Todos cumpriam medida socioeducativa do tipo PSC PS $^{3}$.

Uma vez que o foco do estudo estava sobre jovens em cumprimento de medida socioeducativa em projeto esportivo, foi adotada como critério de inclusão dos sujeitos a designação, pelo Centro de Referência Especializado em Assistência Social (CREAS) ${ }^{4}$, do jovem infrator para o cumprimento de sua medida dentro do projeto esportivo acompanhado. Neste particular, segundo Chauvin e Jounin (2015, p. 130), em uma pesquisa qualitativa,

não faz sentido exigir que uma observação seja "representativa": com efeito, sua lógica não é a da "amostra". [...] O que corrobora todo seu interesse e toda sua "universalidade" é precisamente seu caráter particular, o de um meio situado no tempo, no espaço físico e social, na concretude de uma rede de interconhecimento.

A PSC, conforme Artigo 117 do Estatuto da Criança e do Adolescente - ECA (Brasil, 2015), a prestação de serviços comunitários pode ser cumprida junto a entidades assistenciais, hospitais, escolas, programas comunitários ou projetos sociais. Assim, o projeto que serviu de campo é desenvolvido em Barbacena/MG e atende jovens com idades entre 13 e 18 anos, dentre eles, jovens em conflito com a lei. Atualmente, é o único cadastrado para recebimento de jovens infratores. A pesquisadora atua como coordenadora desse projeto na instituição onde é desenvolvido, o que facilitou a autorização do estudo e a inserção no campo.

Os dados em campo foram obtidos por meio de técnicas etnográficas típicas como observação, diário de campo e entrevistas semiestruturadas. Segundo Wengraf (2004), entrevistas semiestruturadas são aquelas que permitem um ambiente mais amistoso entre entrevistado e entrevistador e, por tal razão, não existe um roteiro de perguntas e sim uma relação de temas para debate. Os temas das entrevistas foram: contatos com o esporte; interesse pelo esporte; opiniões/concepções de esporte; a prática esportiva no projeto; a medida socioeducativa; valores, atitudes e comportamentos.

Foram foco das observações a interação dos jovens com os demais participantes do projeto, com o professor e estagiários; a interação entre eles (jovens infratores); comportamentos e atitudes nas práticas esportivas e prestação de serviços. Esses elementos ajudaram na compreensão das vivências, opiniões, sentidos e significados relativos ao esporte manifestados nas entrevistas.

Observações e entrevistas foram registradas em diário de campo, pois nenhum informante autorizou gravações em vídeo ou em áudio. Nas entrevistas, o registro foi concomitantemente e as observações registradas ao final das atividades.

O projeto é desenvolvido em dois encontros semanais com duas horas cada um. Os jovens da PSC devem cumprir quatro horas em práticas esportivas e quatro horas em atividades de prestação de serviços, totalizando uma jornada semanal de oito horas durante 90 dias. A pesquisadora participou de todas as atividades (esportivas e de prestação de serviços) como auxiliar do professor do projeto. Essa atitude facilitou a aproximação com os jovens e o contato durante as observações. Neste contexto, foi importante manter uma postura reflexiva, atenta aos efeitos da escolha do método sobre a percepção do objeto (CHAUVIN; JOUNIN, 2015).

Os participantes do estudo foram previamente informados sobre a presença e os objetivos da pesquisadora e receberam cópia do Termo de Consentimento Livre e Esclarecido. Os

\footnotetext{
${ }^{3}$ Em Barbacena, são executadas apenas as medidas de meio aberto pela inexistência de instituições específicas para a semiliberdade e a internação.

${ }^{4}$ CREAS - órgão municipal responsável por executar e acompanhar as medidas socioeducativas.
} 
procedimentos da pesquisa foram autorizados pelo Comitê de Ética da Universidade Federal do Espírito Santo, conforme parecer n. ${ }^{\circ}$ 1.936.655.

Os dados foram submetidos à observação analítica, "cuja virtude é a de fazer emergir da situação de pesquisa os conceitos adequados da atividade social dos pesquisados" (BEAUD; WEBER, 2015, p. 195). Segundo os autores, este é um modelo de análise indutivo associado a uma concepção interacionista das relações sociais que se distancia da concepção do pesquisador que age friamente como analista daquilo que à distância observa.

A discussão neste texto se dará a partir de dois eixos: a medida socioeducativa e o esporte como um de seus componentes e o esporte na formação ética e moral dos jovens.

\section{A medida socioeducativa e o esporte como um de seus componentes}

Em atendimento às exigências do CEP e da $2^{\mathrm{a}}$ Vara Infracional da Infância e da Juventude da Comarca de Barbacena, os informantes estão nomeados por Jovem I, Jovem II, Jovem III e Jovem IV.

Segundo o ECA (Brasil, 2015), o papel da medida socioeducativa é oferecer ao jovem a oportunidade de refletir sobre sua infração, buscando a mudança de comportamentos e atitudes. No entanto, no que se refere aos Jovens I, II e III, a medida socioeducativa não tem esse sentido. Para eles, ela está dividida em duas etapas: punição e incentivo. As tarefas de prestação de serviço são classificadas por eles como a parte punitiva da medida, enquanto as vivências esportivas representam uma espécie de incentivo para que eles mantenham a rotina durante o tempo judicialmente estabelecido para o cumprimento da medida socioeducativa. Segundo esses três jovens, o esporte dentro da PSC funciona no sentido oposto àquele pretendido pelo ECA. Serve para distraí-los, permitindo-os esquecer momentaneamente que estão cumprindo uma medida socioeducativa. Eles afirmaram reiteradas vezes que somente quando realizavam as tarefas da PSC é que se lembravam do motivo de estarem ali.

Para esses três jovens, as atividades da PSC são desagradáveis e vergonhosas. Por tal motivo, ocorre a reflexão sobre a infração, no sentido de não desejar passar por tal situação novamente. Em contrapartida, para o CREAS, a expectativa da PSC diretamente ligada a atividades esportivas deveria servir para que os jovens refletissem sobre possibilidades de engajamento profissional futuro no âmbito esportivo. É importante lembrar que o encaminhamento, nesse caso, considera aptidões, interesses e afinidades manifestados pelos próprios jovens, conforme exigências do ECA (Brasil, 2015). Portanto, todos os jovens da PSC encaminhados para o projeto esportivo assim o foram por declararem interesses ou aptidões relacionados à atividade esportiva. Fato que fundamenta a expectativa do CREAS, com a participação dos jovens em atividades coadjuvantes à prática esportiva. $\mathrm{O}$ intuito é despertar neles o interesse em trabalhar com o esporte. Ou seja, idealiza-se a percepção de possibilidades para um futuro profissional dentro de um campo de interesse deles.

Durante as entrevistas com os jovens, foram realizados questionamentos sobre o que o esporte representava para eles naquele contexto - do cumprimento de uma medida socioeducativa. Os discursos produzidos pelos Jovens I, II e III, combinados às observações realizadas em campo, permitiram identificar que, de fato, as práticas esportivas dentro do projeto serviram apenas como estímulo para o cumprimento regular da punição imposta. Os três jovens sempre se referiram à medida socioeducativa como "a punição". Somente o Jovem IV utilizou em seus discursos o termo "medida educativa".

Na perspectiva desses três informantes, o esporte como componente da medida socioeducativa serve como elemento amenizador do tédio presente na prestação de serviços. Nesse sentido, o esporte funciona como a hora do descanso ou do divertimento durante o trabalho imposto pela medida. Um dos jovens, em certo momento, chegou a caracterizar as práticas esportivas como "uma hora de lazer dentro da punição" (Jovem III). Essa caracterização traz à 
tona uma antiga perspectiva funcionalista do lazer, a hora do descanso-divertimento dentro do espaço-tempo do trabalho. Segundo Inácio (1999, p.149), um dos interesses intrínsecos muito criticados antigamente, mas ainda presentes em algumas empresas-instituições que ofertam práticas de lazer aos seus funcionários, é o "controle do tempo disponível, compensação da insatisfação gerada num trabalho estranho e alheio ao trabalhador e desvio das atenções para movimentos operários".

Na percepção desses três jovens, o esporte dentro da medida socioeducativa de PSC funciona como um descanso e, ao mesmo tempo, um momento de diversão. Isso porque as atividades esportivas são oferecidas aos jovens depois de uma hora de prestação de serviços e antes de terem de cumprir mais uma hora nas mesmas atividades. Nessa lógica, as práticas esportivas servem tanto para quebrar a monotonia e o tédio da prestação de serviços como ajudar a reduzir o tempo de envolvimento com esse tipo de atividade. Ou seja, para eles, seria muito mais penoso ter que cumprir oito horas semanais somente em atividades de prestação de serviços a cumprir quatro horas em prestação de serviços e quatro horas em vivências esportivas, como ocorre atualmente.

Já para o Jovem IV, o esporte é caracterizado como um elemento fundamental dentro da medida socioeducativa. Na sua visão, existe uma relação direta entre os valores do esporte e os valores da vida em sociedade. A prática esportiva dentro da medida pode auxiliar tanto na reflexão sobre os motivos que o levaram a cometer a infração bem como na "avaliação e escolha de melhores condutas para situações diversas da vida, sejam elas positivas ou conflituosas" (Jovem IV). Segundo ele, existe uma conexão entre as condutas adotadas por uma pessoa dentro do jogo esportivo e suas condutas na vida em sociedade. Tais argumentos embasam sua opinião sobre o papel do esporte como mecanismo de ação em medidas socioeducativas.

Conforme ainda o Jovem IV, o esporte aprimora habilidades motoras e sociais quando permite aos praticantes a valorização de seus potenciais individuais a partir do convívio sob o mesmo conjunto de normas, ensinando o respeito mútuo e o respeito às regras. Para ele, o esporte ensina que o bom andamento do jogo depende tanto "do desempenho físico-motor e do desempenho ético e moral de cada jogador" (Jovem IV). Por isso, na sua visão, não basta que os jogadores conheçam as regras do jogo - é preciso que eles compreendam os motivos que justificam a existência delas.

\section{O esporte na formação ética e moral dos jovens}

Quando as entrevistas abordavam temas relacionados ao esporte e ao aprendizado de valores, novamente as opiniões dos Jovens I, II e III divergiam das opiniões do Jovem IV. Para os Jovens I, II e III, o esporte tem apenas dois propósitos: ou serve como opção para distrair as pessoas em seus momentos de lazer ou como meio de vida quando um praticante consegue se profissionalizar. Já a compreensão de esporte do Jovem IV extrapola a classificação dualista feita pelos demais. Para ele, o esporte tem outras competências e características. Ele afirmou, reiteradas vezes, que a prática esportiva pode ajudar na melhora de condições físico-motoras e no desenvolvimento de outras habilidades como: "controle das emoções; racionalização do jogo e da vida; criatividade para lidar com situações adversas; estabelecer relações sociais com outras pessoas, sejam elas parceiras ou adversárias" (Jovem IV).

Segundo esse mesmo jovem, a compreensão que desenvolveu acerca do esporte teve influência de seu professor de Educação Física na escola, o qual destacava outros elementos além da habilidade motora ou do nível técnico dos alunos. Segundo relatou, seu professor estimulava todos à prática esportiva, não apenas os mais habilidosos, destacando a cooperação, o respeito, a liderança, a criatividade e o raciocínio como elementos também importantes ao jogo. 
Já os relatos dos Jovens I, II e III apontam para vivências escolares bem diferentes. Segundo eles, nas aulas de Educação Física, o conteúdo predominante era o esporte, mais especificamente, os esportes coletivos. Aliada a isso, estava a valorização dos mais habilidosos, restringindo a aula à prática esportiva para aqueles que "já sabiam jogar" (Jovem II). Ainda segundo esses três jovens, houve períodos escolares em que os alunos que praticavam esporte fora da escola eram liberados das aulas e outros períodos em que as aulas assumiam caráter de treinamento, com o intuito de preparar equipes para os jogos escolares.

Embora não tenha sido intenção do estudo analisar os processos pedagógicos e/ou os professores de Educação Física desses jovens, os relatos sobre as vivências esportivas no ambiente escolar auxiliaram a identificar elementos que podem ter influenciado suas concepções e entendimentos acerca do esporte. Richard Bailey (2005) realizou um estudo de revisão sobre as relações entre o esporte, a Educação Física escolar e a inclusão social no Reino Unido. Dentre outras questões, o autor discute as influências do ambiente moral onde ocorrem as práticas esportivas nos aprendizados obtidos por meio dessas práticas. Segundo ele, a aprendizagem social no esporte se torna mais eficaz quando os professores de Educação Física escolar (ou agentes esportivos - o que ocorre em algumas instituições educacionais, clubes e projetos sociais) conseguem construir um ambiente moral positivo para o estabelecimento das relações interpessoais dos praticantes, deles com o esporte e com os valores desejados.

Bailey (2005) afirma que não é o fenômeno esportivo em si que educa e sim as relações interpessoais construídas em torno dele. Mas, para isso, é importante que todos participem e não apenas aqueles dotados de melhores habilidades. Segundo o autor, o engajamento em atividades esportivas deve considerar outras habilidades além da dimensão físico-motora para que de fato valores positivos sejam apreendidos e efetivados na vida adulta. Esses elementos não foram percebidos nos discursos de três dos quatro jovens acompanhados em campo.

Ainda sobre as contribuições que o esporte pode trazer à formação ética e moral, o Jovem IV apresentou opinião distinta dos demais. Para os Jovens I, II e III, o esporte tem um conjunto de regras que funciona como um código de conduta que deve ser conhecido e respeitado pelos praticantes para o bom andamento do jogo. No entanto, para eles, esse código de conduta serve apenas para o período de duração do jogo esportivo. Eles afirmaram que as "leis do esporte" (Jovem I, Jovem II) não se aplicam na vida em sociedade. Não há relação entre o que ocorre em campo/quadra e o que ocorre na vida real. Na perspectiva desses jovens, não existem relações ou conexões entre as normas de conduta no/do jogo esportivo com as normas de conduta na/da sociedade. Da mesma maneira, no entendimento deles, as relações estabelecidas dentro do jogo esportivo diferem daquelas estabelecidas no meio social.

Os mesmos três jovens utilizaram como argumento o fato de terem cometido uma infração mesmo conhecendo as regras sociais e compreendendo as implicações do descumprimento delas. Segundo os informantes, eles conhecem as regras do jogo esportivo e as respeitam para terem maiores chances de vencer na partida. No entanto, na vida social, embora conheçam as regras de conduta, nem sempre as respeitam e fazem isso de maneira consciente, na expectativa de não serem flagrados cometendo o desvio. Eles admitem que, tanto no jogo esportivo como na vida em sociedade, existem punições para aqueles que infringem as regras, mas isso não significa afirmar que aqueles que respeitam as regras do jogo esportivo também respeitarão as regras da vida social. Eles se colocam como exemplo para fundamentar a afirmação.

Para esses três jovens, a configuração das relações no jogo esportivo em nada se assemelha ou se aproxima da configuração das relações estabelecidas na vida social. Todavia, há em suas falas indícios de que eles reconhecem a existência de um conjunto de códigos em ambas as situações - jogo esportivo e vida social - e que, em determinadas circunstâncias, esse conjunto de códigos pode apresentar algumas semelhanças e aproximações. 
Já para o Jovem IV, compreender o papel das regras empregadas no jogo esportivo e assimilar sua importância dentro da dinâmica do esporte é fundamental para compreender as mesmas questões dentro da sociedade em que se vive. Para ele, existem relações entre o conjunto de regras e valores do/no esporte e o conjunto de regras e valores necessários para a vida em sociedade. A notória diferença entre a opinião desse jovem para aquela expressa pelos Jovens I, II e III está no fato de que, na visão destes, as regras do esporte se fazem necessárias para que todos saibam como jogar, enquanto para o Jovem IV as regras do jogo esportivo contribuem para a formação moral e ética daqueles que jogam. "Elas auxiliam na compreensão das normas e condutas desejáveis para a vida social" (Jovem IV).

Norbert Elias $(2001,1994)$ desenvolveu importantes estudos sobre as mudanças ocorridas no modo de vida e no comportamento das sociedades com base na análise da sociedade de corte, contribuindo para o desenvolvimento da sociologia configuracional. Esta, por sua vez, tem como categoria central, para a análise e a compreensão da sociedade, a competição que se manifesta no conjunto das relações sociais. É nesse sentido que a expressão 'jogo', adotada por Elias $(2001,1994)$, assumiu condição significativa no processo de análise das relações sociais. Por tais razões, esse autor acabou definindo a organização social que analisava em seus estudos como o "grande jogo". Elias não utilizou essa expressão de maneira metafórica, mas, sim, como uma descrição das análises sobre as relações sociais manifestas naquela configuração de sociedade. Para o autor, o esporte e a sociedade são estruturas de competição, portanto, podem ser analisados como um jogo de ação estrutural. Na sociologia configuracional, o jogo acaba assumindo a condição de instrumento de análise e também de noção realista da sociedade.

O Jovem IV concebe o esporte como simulacro da vida em sociedade. Para ele, a dinâmica estrutural do jogo esportivo apresenta semelhanças com a dinâmica estrutural da vida em sociedade, uma vez que o jogo esportivo é composto pela definição de papeis e funções; determina espaços/áreas permitidos e proibidos; conta com um conjunto de regras orientador de condutas; impõe punições às infrações; dispõe de uma equipe de supervisão; estabelece tempos específicos para o jogo ativo e o intervalo (trabalho e descanso). Para ele, estas são características do esporte que ajudam na formação ética e moral dos praticantes.

Considerados as observações e os discursos, notou-se que a percepção que distancia ou aproxima o conjunto de códigos do esporte do conjunto de códigos da vida social está alicerçada na concepção restrita ou ampliada de esporte que os sujeitos desenvolveram. No contexto específico do estudo, pode-se deduzir que a maneira como o esporte foi tratado no ambiente escolar influenciou as concepções desenvolvidas pelos jovens e estas foram levadas para dentro das práticas durante a medida socioeducativa.

\section{Conclusões}

Com base nas análises, ficou evidente que o esporte funciona, para a maior parte dos jovens acompanhados, como um elemento que torna a medida socioeducativa menos desagradável. Para três dos quatro jovens em estudo, o esporte assumiu a função de elemento amenizador do tédio e do desconforto provocado pelas atividades de prestação de serviço impostas pela medida.

Outro resultado relevante é a convicção dos mesmos três jovens de que o esporte não oferece potencial significativo na formação ética e moral. Eles evidenciam em seus discursos que as posturas e condutas adotadas na prática esportiva não se refletem na vida real, sejam elas positivas, sejam elas negativas. Colocam a prática esportiva numa dimensão distinta e desconexa da vida real, sem qualquer possibilidade de tranferência de aprendizados de uma para a outra. $\mathrm{O}$ que reforça suas convicções de que o esporte dentro da medida socioeducativa serve apenas para distraí-los e não para ajudá-los na mudança de comportamentos e atitudes. 
Por fim, identificaram-se nos quatro jovens influências significativas das vivências esportivas desfrutadas no ambiente escolar na construção de suas concepções e de seus entendimentos acerca do esporte. O que, por sua vez, acaba gerando interferências (positivas ou negativas) na ressocialização idealizada para os jovens via medida socioeducativa a partir do esporte.

\title{
SPORTING IN RE-SOCALIZATION TO YOUNG OFFENDERS - A CASE STUDY
}

\begin{abstract}
In general there is a popular idea about the sport and values education. This ideia carrie out a suppose potential within social actions toward a reduction the crime in childhood and youth. We realize a study for to identify and try to understand the conceptions about the sport adopted for four young offenders into a social project. These young were doing comunitary services as a social and educational measure. Three in four these young thinking that the sport doesn't help then reflect about the crime that they committed. They believe that sport can't influence their behavior in social life, too.
\end{abstract}

Keywords: Adolscent. Sports. Projects. Social behavior.

\section{DEPORTE EN REHABILITACIÓN DE JÓVENES EN CONFLICTO CON LA LEY - ESTUDIO DE CASO}

\section{Resumen}

Existe en torno al deporte un discurso bastante difundido sobre sus potencialidades sin trato con valores éticos y morales. Embutida ese discurso es una premisa que o apunta como herramienta de alto potencial dentro de acciones sociales que intención, dentre otros, combater una criminalidad en la infancia y juventude. Objetivo del estudio para identificar y probar los sentidos y los significados del deporte para los jóvenes en conflicto con la ley inserta en un proyecto social de deporte para el cumplimiento de la medida socioeducativa del tipo PSC. Para los tres jóvenes, el deporte no ayuda a reflexionar sobre una infracción cometida y muy poco influenciar sus comportamientos y atitudes en la vida en sociedad.

Palabras-clave: Adolescente. Deportes. Proyectos. Conducta social.

\section{Referências}

ANTUNES, S. E. Retrato preliminar da pesquisa em educação física sobre projetos esportivos no âmbito social. In: CONGRESSO BRASILEIRO DE CIÊNCIAS DO ESPORTE, 19; CONGRESSO INTERNACIONAL DE CIÊNCIAS DO ESPORTE, 4. Vitória, 2015. $\begin{array}{llllll}\text { Anais..., } & \text { v. } & 1, & \text { p. } & 1-13 . & \text { Disponível }\end{array}$ <http://congressos.cbce.org.br/index.php/conbrace2015/6conice/paper/view/7375/3437> Acesso em: 27 ago. 2017.

BAILEY, R. Evaluating the relationship between physical education, sport and social inclusion. Educational Review. v. 1, n. 57, p. 71-90, 2005.

BEAUD, S.; WEBER, F. O raciocínio etnográfico. In: PAUGAM, S. (Coord.) A pesquisa sociológica. Petrópolis: Vozes, 2015. p. 185-201. 
BRASIL. Estatuto da Criança e do Adolescente. 13 ed. Brasília: Edições Câmara, 2015. Disponível em: <http://bd.camara.gov.br/bd/handle/bdcamara/18403> Acesso em: 16 jan. 2017.

CHAUVIN, S.; JOUNIN, N. A Observação direta. In: PAUGAM, S. (Coord.) A pesquisa sociológica. Petrópolis: Vozes, 2015. p. 124-140.

DANISH, S. J.; FORNERIS, T.; HODGE, K.; HEKE, I. Enhancing youth development through sport. World Leisure Journal, v. 3, n. 46, p. 38-49, 2011.

ELIAS, N. A sociedade de corte. Rio de Janeiro: Zahar, 2001.

O processo civilizador: uma história dos costumes. Rio de Janeiro: Zahar, 1994. v. 1 .

HAMMERSLEY, M.; ATKINSON, P. Ethnography: principles in practice. London/New York: Routledge, 1999.

HOLT, N. L.; NELLY, K. C. Positive youth development throught sport: a review. Revista Iberoamericana de Psicologia del Ejercicio y el Deporte, Canarias v. 2, n. 6, p. 299-316, 2011.

INÁCIO, H. L. D de. Os interesses contemporâneos no lazer-empresa. In: MARCELLINO, N. C. (Org.). Lazer \& empresa. 3 ed. Campinas: Papirus, 1999. p.149-162.

JANSSENS, J. Education through sport: an overview of good practices in Europe. Nieuwegein: Arko Sports Media, 2004.

LAVILLE, C.; DIONNE, J. A construção do saber: manual de metodologia da pesquisa em ciências humanas. Tradução de Heloisa Monteiro e Francisco Settineri. Porto Alegre: Artmed, 1999.

NICHOLS, G. Sport and crime reduction: the role of sports in tackling youth crime. Abington: Routledge, 2007.

The impact of sports programmes on youth crime. 2004. $281 \mathrm{f}$. Thesis (Doctorate in Philosophy) - Department of Law, Sheffield University, U.K., 2004.

STEENBERGEN, J.; TAMBOER, J. Ethics and the double character of sport: an attempt to systematize discussion of the ethics of sport. In: MCNAMEE, M. J.; PARRY, S. J. (Ed.). Ethics and sport. London: E \& FN Spon, 1998. p. 35-54.

THOMPSON, A. A. Do compromisso à eficiência? Os caminhos do terceiro setor na América Latina. In: IOSCHPE, E. $3^{\circ}$ Setor: desenvolvimento social sustentado. Rio de Janeiro: Paz e Terra, 2005. p. 41-48.

WENGRAF, T. Qualitative research interviewing "C biographic narrative and semistructured methods. $2^{\text {a }}$ Reprinted. London: Sage Publications, 2004. Disponível em: <https://books.google.com.br/books?id=c2b6jQ8g3sAC\&pg=PR3\&hI=ptBR\&source=gbs_sel ected_pages\&cad=3\#v=onepage\&q\&f=true>. Acesso em: 25 ago. 2017. 
ZALUAR, A. Cidadãos não vão ao paraíso. Campinas: Ed. da Universidade Estadual de Campinas, 1994.

Recebido em: 25/04/2017

Revisado em: 11/11/2017

Aprovado em: 13/11/2017

Endereço para correspondência:

scheilaeantunes@gmail.com

Scheila Espindola Antunes

Instituto Federal de Educação, Ciência e Tecnologia do Sudeste de Minas Gerais

Rua Monsenhor José Augusto, 204

São José

36205-018 - Barbacena, MG - Brasil 